\title{
USING BREWER'S YEAST AND GINGER IN THE MANAGEMENT OF CONSTIPATION-PREDOMINANT IRRITABLE BOWEL SYNDROME: A RANDOMIZED DOUBLE-BLIND PLACEBO-CONTROLLED TRIAL
}

\author{
ZAINAB G AL-JASSIM* \\ Department of Pharmacology, College of Dentistry, University of Baghdad, Baghdad, Iraq. Email: ph.zainab86@yahoo.com \\ Received: 12 November 2018, Revised and Accepted: 05 January 2019
}

\begin{abstract}
Objective: The objective of the present study is to confirm and/or prove the beneficial outcomes from using Brewer's yeast and Ginger in constipationpredominant irritable bowel syndrome (IBS-C) subjects compared to placebo.

Methods: A total of 45 patients suffering from IBS-C were enrolled in a double-blind placebo-controlled study as defined by Rome III criteria. Parallel groups were randomly assigned in this study: A placebo group, Brewer's yeast group, and ginger group, taken daily for 20 days. IBS severity scale and visual analog scale for IBS (VAS-IBS) were used to assess the severity of pain, abdominal distention, and constipation (IBS-C) subjects. The data were measured at 3 times: At 0 time (T0), after 10 days of treatment (T10), and after 20 days of treatment (T20) for the three treatment groups.
\end{abstract}

Results: Intragroup analysis showed a clinically significant reduction in the symptoms of abdominal pain, distention, and constipation, in the Brewer's yeast group compared to placebo after the 20 days of the study. There was also a significant reduction of abdominal distention and constipation symptoms in the ginger group throughout the study.

Conclusion: This study reveals the beneficial effects of Brewer's yeast and ginger in reducing troublesome gastrointestinal symptoms in subjects with IBS-C and holds the promise to use them in IBS-C patient.

Keywords: Irritable bowel syndrome, Constipation-predominant irritable bowel syndrome background, Brewer's yeast, Ginger.

(C) 2019 The Authors. Published by Innovare Academic Sciences Pvt Ltd. This is an open access article under the CC BY license (http://creativecommons. org/licenses/by/4. 0/) DOI: http://dx.doi.org/10.22159/ajpcr.2019.v12i3.30716

\section{INTRODUCTION}

Irritable bowel syndrome (IBS) is a widespread gastrointestinal disorder with symptoms of abdominal pain, discomfort, cramping, and alternating bowel habits of constipation and diarrhea [1]. Till now, there are no clear causes and there is no diagnostic tool to screen and diagnose people with IBS [2]. The treatment mainly concentrates on the relief of symptoms to have a normal quality of life [3].

It can be classified into three specific forms: Constipation-predominant IBS-C, diarrhea-predominant IBS-D, or mixed symptoms of constipation and diarrhea (IBS-M) [4]. Since there are no clear causes, treatment focuses on symptoms relief, which can be managed by controlling stress, avoiding high-gas foods, exercising, drinking plenty of fluids, get enough sleep, and using fiber supplements, antidiarrheal, antispasmodic, and antidepressant medications $[5,6]$.

This study concentrates on constipation-predominant IBS-C, which can be defined as constipation associated with abdominal pain and discomfort that is generally relieved by defecation [7], affects about $34 \%$ of the IBS population [8,9]. Recent studies show that IBS-C is associated with higher rates of functional impairment, as compared to other subtypes of IBS [10-12]. The use of traditional laxatives was unsatisfactory in the treatment of IBS-C [13]. Till now, there is no drug therapy that can be used safely and chronically to treat all of the symptoms of IBS-C and improves the patient's health-related quality of life [14].

Brewer's yeast is made from Saccharomyces cerevisiae, which is a one-celled fungus. It is used as a nutritional supplement and a source of Vitamin B complex, selenium, and chromium and considered a probiotic that can help to maintain the proper function of the digestive tract $[15,16]$. It also has been found to ease and reduce constipation. It will initially produce gases in the colon and then helps with constipation relief and patient comfort [17]. Brewer's yeast increases the good bacteria in the colon and reduces the bad which will help in maintaining normal bowel movement [18-20].

On the other hand, ginger is an important traditional herb that has been used by ancient Chinese and Indian people [21]. Ginger was used primarily for it antiemetic, anti-inflammatory, and analgesic properties that have been proven from many previous studies [22]. Furthermore, it was found to improve blood circulation, lower blood cholesterol, and lower blood glucose and treat migraine headaches [23-25]. It was found to facilitate digestion, improve bowel motion, decrease nausea and vomiting, and relieve constipation and flatulence [26-29]. Thus, ginger could be a beneficial and generally safe medicine that can reduce the pain and flatulence and improves bowel activity in IBS-C patients.

This study aimed to perform a randomized placebo-controlled clinical trial on IBS-C subjects to confirm and/or prove the beneficial outcomes from using Brewer's yeast and ginger in IBS-C subjects.

\section{METHODS}

\section{Study design and population}

A total of 45 outpatients with constipation-predominant IBS-C were included in this multicenter double-blind controlled study. Parallel groups of 15 subjects were randomly assigned in this study: A placebo group, $500 \mathrm{mg}$ Brewer's yeast group and $1 \mathrm{~g}$ ginger group, taken daily for 20 days. Age of the subjects selected was 18 and more seasoned with a physician conclusion of IBS with constipation confirmed by Rome III criteria [30].

A self-reported questionnaire, using IBS severity scale (IBS-SS) and visual analog scale of IBS (VAS-IBS) were used to assess the 
severity of pain, abdominal distention, and constipation (IBS-C) subjects rated on a $0-100$ scale, where $0=$ none symptom and $100=$ more severe symptom $[31,32]$. The data were measured at 3 times: At 0 time before treatment (T0), after 10 days of treatment (T10), and after 20 days of treatment (T20) for the three treatment groups. Age of the subjects involved was between 18 and 64 years.

A written informed patient consent was taken from all the volunteers in the study. Exclusion criteria were as follows: Pregnant or breastfeeding females, the presence of uncontrolled cardiovascular disease, diabetes mellitus (type I or II), psychological conditions, renal or hepatic sickness, uncontrolled thyroid disease, Parkinson's disease, previous gastrointestinal surgery, allergy to ginger or S. cerevisiae (Brewer's yeast), and exclude patients taking medications that are frequently associated with constipation such as contraceptives, proton-pump inhibitors, beta-blockers, ACE inhibitors, calcium antagonists, statins, diuretics, and barbiturates. Furthermore, avoid patients with gout or who are taking monoamine oxidase inhibitors which interact with Brewer yeast. In addition, avoid taking laxative drugs for constipation such as bisacodyl, psyllium, senna, macrogol, lactulose, sodium bicarbonate, sorbitol, prucalopride, and Glauber's salt. Any of the previous factors and conditions was excluded as possible during the 20 days of study.

\section{Assessment measures}

Self-reported questionnaire, using IBS-SS, was used to assess the severe abdominal pain and abdominal distension or bloating rated on a 0-100 scale. The severity of constipation was assessed using VAS for IBS rated from 0 to 100. The data were measured at 3 times: At 0 time before treatment (T0), after 10 days of treatment (T10), and after 20 days of treatment (T20) for the three groups of patients.

\section{Treatment}

Patients were randomized to get either the treatment or placebo, once, day by day for 20 days of study period. Subjects were submitted to three control visits through the span of 20 days at day 0 and two follow-up visits at days 10 and 20 .

The placebo capsules were prepared to contain brown sugar. Brewer's yeast (S. cerevisiae) $500 \mathrm{mg}$ tablets of Adrien Gagnon Company were used in the study. Ginger root powder (Zingiber officinale Roscoe, Zingiberaceae) was capsulated in a dose of $1 \mathrm{~g}$ daily capsule provided by simply organic company.

\section{Statistical analysis}

All data are reported as mean \pm SD. IBS-SS and VAS of IBS were used to assess the severity of pain, abdominal distention, and constipation in IBS-C subjects rated on a $0-100$ scale, where $0=$ none symptom and $100=$ more severe symptom $[31,32]$. Statistical analysis of data was performed using Statistical Analysis System (SAS) - version 9.1 (SAS. 2010). Two-way ANOVA and least significant differences post hoc test were performed to assess significant differences among means. $p<0.05$ is considered statistically significant.

\section{RESULTS}

A total of 45 subjects with IBS-C were included into this study and were successfully randomized to be either in placebo group $(n=15)$ or active treatment groups: Brewer's yeast $(n=15)$ and ginger group $(n=15)$. The medications were received daily for 20 days. Data were collected at three different times (day zero T0, after 10 days T10, and after 20 days T20). When the study begins, all the subjects show a high adherence to the treatment. Fig. 1 represents the consort flowchart of the study.

The mean values + SD of the scores, taken from the IBS-SS scale, for the abdominal pain and distention and from VAS-IBS scale applied for the severity of constipation, are shown in Table 1 for the different groups and times. The results revealed no statically significant differences at time zero for all groups with all symptoms measured, at this time, no treatment has been received yet.

Intergroup analysis of pain measures revealed a statistically significant reduction of pain in the Brewer's yeast group at the different times $(\mathrm{T} 0=40.26 \pm 3.66, \mathrm{~T} 10=31.80 \pm 2.73$, and $\mathrm{T} 20=26.66 \pm 2.70 ; \mathrm{p}<0.05)$, whereas the reduction in the ginger group not quite significant $(\mathrm{T} 0=39.60 \pm 3.29, \mathrm{~T} 10=36.06 \pm 3.46$, and $\mathrm{T} 20=31.73 \pm 3.21 ; \mathrm{p}<0.05)$. The placebo group shows no statistically significant difference as shown in Table 1. Furthermore, if T20 results were compared, for the pain measures, at the three treatment groups, a significant reduction occurs mainly in the Brewer's yeast group (placebo $=37.66 \pm 2.89$, Brewer's yeast $=26.66 \pm 2.70$, and ginger $=31.73 \pm 3.21 ; \mathrm{p}<0.05$ ) . Intergroup analysis of abdominal distention measures revealed a statistically significant reduction of distention in the Brewer's yeast group between $\mathrm{T} 0$ and the times $\mathrm{T} 10$ and $\mathrm{T} 20(\mathrm{~T} 0=69.80 \pm 3.73$, T10 $=53.53 \pm 3.37$, and $\mathrm{T} 20=45.00 \pm 3.21 ; \mathrm{p}<0.05$ ), similar significant reduction was in ginger group $(\mathrm{T} 0=68.73 \pm 3.68, \mathrm{~T} 10=53.53 \pm 3.37$, and $\mathrm{T} 20=50.00 \pm 2.88 ; \mathrm{p}<0.05$ ). The placebo group shows no statistically significant difference as shown in Table 1. Furthermore, if T20 results were compared, for the abdominal distention measures, at the three treatment groups, a significant reduction occurs in the Brewer's yeast and ginger groups compared to placebo (placebo $=59.33 \pm 2.43$, Brewer's yeast $=45.00 \pm 3.21$, and ginger $=50.00 \pm 2.88 ; \mathrm{p}<0.05$ ).

Intergroup analysis for the constipation severity measures revealed a small statistically reduction in constipation severity in the placebo group at $\mathrm{T} 0$ compared to times $\mathrm{T} 10$ and $\mathrm{T} 20$ but still severe on the VASIBS scores $(\mathrm{T} 0=75.60 \pm 2.43, \mathrm{~T} 10=66.93 \pm 1.96$, and $\mathrm{T} 20=65.86 \pm 2.64$; $\mathrm{p}<0.05$ ). Analysis also revealed a statistically significant reduction of constipation severity in the Brewer's yeast group between T0 and the times $\mathrm{T} 10$ and $\mathrm{T} 20(\mathrm{~T} 0=67.80 \pm 3.72, \mathrm{~T} 10=48.13 \pm 3.22$, and $\mathrm{T} 20=42.93 \pm 3.28 ; \mathrm{p}<0.05)$. Similar significant reduction was in ginger group $(\mathrm{T} 0=70.66 \pm 3.09, \mathrm{~T} 10=55.26 \pm 3.03$, and $\mathrm{T} 20=49.13 \pm 2.73$;

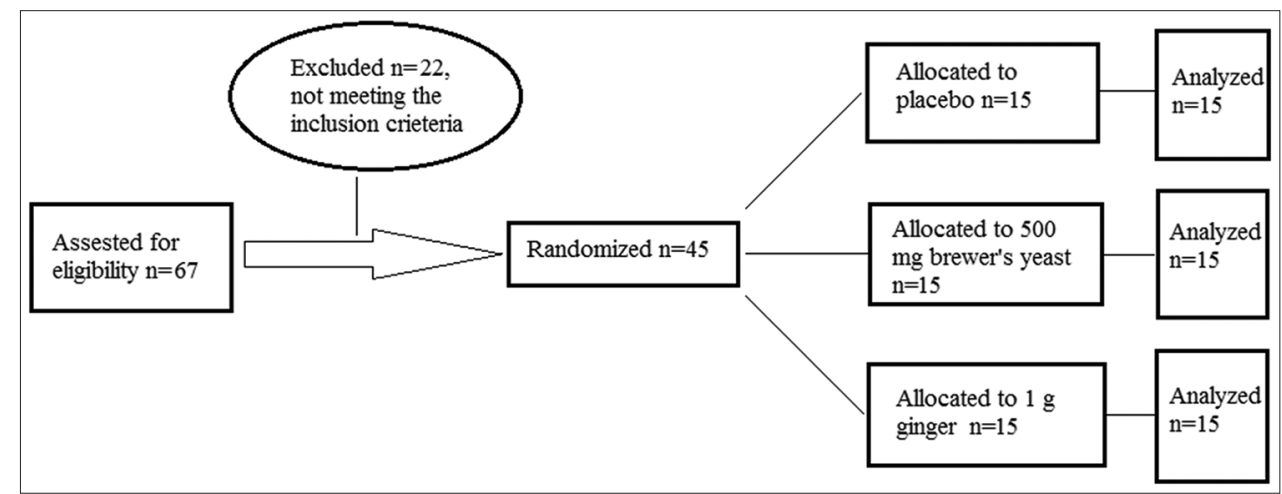

Fig. 1: Consort flow diagram 
Table 1: Primary outcomes in placebo, Brewer's yeast, and ginger groups measured by IBS-SS and VAS-IBS scores, as mean value+SD, at three different times

\begin{tabular}{|c|c|c|c|c|}
\hline Measures & Treatment groups & T 0 & T 10 & T 20 \\
\hline \multirow[t]{3}{*}{ Abdominal pain (IBS-SS) } & Placebo & $\mathrm{A} 42.46 \pm 2.94 \mathrm{a}$ & A36.33 $\pm 2.85 a$ & $\mathrm{~A} 37.66 \pm 2.89 \mathrm{a}$ \\
\hline & Brewer's yeast & $\mathrm{A} 40.26 \pm 3.66 \mathrm{a}$ & $\mathrm{AB} 31.80 \pm 2.73 \mathrm{a}$ & $\mathrm{B} 26.66 \pm 2.70 \mathrm{~b}$ \\
\hline & Ginger & $\mathrm{A} 39.60 \pm 3.29 \mathrm{a}$ & $\mathrm{A} 36.06 \pm 3.46 \mathrm{a}$ & $\mathrm{A} 31.73 \pm 3.21 \mathrm{ab}$ \\
\hline LSD & & 8.6825 & & \\
\hline \multirow[t]{3}{*}{ Abdominal distention (IBS-SS) } & Placebo & $\mathrm{A} 66.33 \pm 2.72 \mathrm{a}$ & $\mathrm{A} 61.06 \pm 2.62 \mathrm{a}$ & A59.33 $\pm 2.43 a$ \\
\hline & Brewer's yeast & $\mathrm{A} 69.80 \pm 3.73 \mathrm{a}$ & $\mathrm{B} 53.53 \pm 3.37 \mathrm{a}$ & $\mathrm{B} 45.00 \pm 3.21 \mathrm{~b}$ \\
\hline & Ginger & $A 68.73 \pm 3.68 \mathrm{a}$ & $\mathrm{B} 52.73 \pm 2.48 \mathrm{a}$ & $\mathrm{B} 50.00 \pm 2.88 \mathrm{~b}$ \\
\hline \multirow[t]{3}{*}{ Constipation severity (VAS-IBS) } & Placebo & $\mathrm{A} 75.60 \pm 2.43 \mathrm{a}$ & $\mathrm{B} 66.93 \pm 1.96 \mathrm{a}$ & $\mathrm{B} 65.86 \pm 2.64 \mathrm{a}$ \\
\hline & Brewer's yeast & $\mathrm{A} 67.80 \pm 3.72 \mathrm{a}$ & $\mathrm{B} 48.13 \pm 3.22 \mathrm{~b}$ & $\mathrm{~B} 42.93 \pm 3.28 \mathrm{~b}$ \\
\hline & Ginger & A70.66 $\pm 3.09 a$ & B55.26 $\pm 3.03 b$ & B $49.13 \pm 2.73 b$ \\
\hline LSD & & 8.2465 & & \\
\hline
\end{tabular}

Values are expressed as mean \pm standard deviation. Means with a different capital letter in the same row significantly different (p<0.05). Means with a different small letter in the same column significantly different ( $\mathrm{p}<0.05$ ). LSD: Least significant differences (T0 [before treatment], T10 [after 10 days of treatment], and T20 [after 20 day of treatment])

$\mathrm{p}<0.05)$. Furthermore, ifT10 results were compared, for the constipation severity measures, at the three treatment groups, a significant reduction occurs in the Brewer's yeast and ginger groups compared with placebo (placebo $=66.93 \pm 1.96$, Brewer's yeast $=42.93 \pm 3.28$, and ginger $=$ $55.26 \pm 3.03 ; \mathrm{p}<0.05$ ), similar reductions at $\mathrm{T} 20$ (placebo $=65.86 \pm 2.64$, Brewer's yeast $=45.00 \pm 3.21$, and ginger $=49.13 \pm 2.73 ; \mathrm{p}<0.05$ ).

\section{DISCUSSION}

Constipation and IBS are common complaints and challenges nowadays, especially for older adults. The available therapies provide satisfaction in $<40 \%$ of IBS population [33]. Lifestyle modification, secondary and medication-induced causes, and non-pharmacologic treatment should be the first step to avoid unnecessary drug therapy [8]. Many factors can increase the risk of IBS, in general, and IBS-C, in particular, such as age, diet type (low fiber, high in saturated fat, and fermentable carbohydrate), being obese, low exercise fitness, being a woman, and having psychosocial and environmental stress [34-37].

Although the pathogenesis of IBS still unclear, evidence proved a strong relation with stress, abnormal intestinal motility, diet, and gut microbiota [38]. Stress was found to be an important factor that can disrupt normal bowel movements and contribute to IBS symptoms and constipation [39]. Thus, in the placebo groups in this current study, a number of patients show improvements in the IBS-C symptoms, despite having no active treatment. This indicates the relation between the psychological state of patient and IBS symptoms. In the previous years, the importance of psychosocial and environmental stressors on the pathogenesis IBS has researched widely [39]. Stress may influence diverse physiologic elements of the gastrointestinal tract including gastric secretions, gastrointestinal motility, mucosal penetrability, visceral sensitivity, and mucosal blood flow $[40,41]$. Furthermore, stress has been shown to have a strong effect on gut microbiota. It has been found that catecholamines could change the growth, motility, and virulence of gut bacteria which can play an important role in IBS $[42,43]$.

Gastrointestinal microbiota and probiotics have been proved to be beneficial to the host by exerting various effects such as immunomodulation, competition with pathogens for nutrients and thus growth suppression, and production of antibacterial toxin (bacteriocins) [44]. Probiotics also proved to have a positive impact on the gut-brain axis and thus could be named "psychobiotics" [45]. In a 1-month human study, probiotics have found to alter mental status compared to placebo, using functional magnetic resonance imaging [46]. Many studies have linked the abundance of bacteria in the gut with IBS occurrence. This relationship is substantially complex and includes a number of mechanisms which remain to be not fully clarified $[47,48]$. The benefits from using probiotics in alleviating IBS symptoms have been demonstrated by many studies, but more researches have to be conducted to prove the clinical efficacy and mechanistic basis of probiotic in the management of IBS.

S. cerevisiae is a yeast species that has been contributory to winemaking, baking, and brewing [15]. Brewer's yeast tablets are made from $S$. cerevisiae species. This probiotic has been researched in IBS patients and shows advantageous properties to IBS symptoms. Four previous, randomized clinical trials have studied the effects of S. cerevisiae on IBS and showed that $S$. cerevisiae could alleviate IBS symptoms such as abdominal pain, abdominal distention, and constipation [18-20,49]. This current study strengthens and confirms the beneficial effects of S. cerevisiae on the symptoms of IBS-C. There was a significant reduction in the gastrointestinal symptoms measured including pain, distention, and constipation severity. The results were remarkable, especially after 20 days of the treatment. The abdominal pain was decreased 13.6 points on IBS-SS scale (33.8\% reduction). The abdominal distention or bloating decreased 24.8 points on IBS-SS scale (35.5\% reduction). Constipation decreased 24.9 points on VAS-IBS scale (36.7\% reduction).

Ginger is a safe, widely available, and low-cost herb that has been proved to have many useful antiemetics, anti-inflammatory, sedative, and analgesic properties, in addition to its beneficial effects on blood circulation [22]. Concerning the gastrointestinal diseases, ginger was found to be valuable in alleviating many GIT symptoms such as pain, bloating, constipation, nausea and vomiting, and improving gut motility $[26,27,29]$. For these beneficial GIT outcomes, it has been studied in IBS and IBS-C subjects and proved to be a useful future medicine $[28,29]$. This current study agrees with other previous studies and confirms the useful effects of ginger in the management of IBS-C patients and alleviating the symptoms. There was a clinically significant reduction in the abdominal distention and constipation severity variables of IBS-C. The pain was reduced in about $19.9 \%$, abdominal distention $27.3 \%$, and constipation $30.5 \%$, throughout the 20 days of the study.

As a conclusion, Brewer's yeast and ginger are two promising, multiadvantageous, natural, widely available, and low-cost future medications for IBS-C patients. These compounds need to be studied extensively, on the bases of their mechanisms and whole effects on the body, to reach the proper cure for IBS-C.

\section{CONCLUSION}

This study reveals the beneficial effects of Brewer's yeast and ginger in reducing troublesome gastrointestinal symptoms in subjects with IBS-C and holds the promise to use them in IBS-C patient.

\section{ACKNOWLEDGMENTS}

The author would like to thank Dr. Firas R. Al-Samarai for his assistance in the data analysis. 


\section{AUTHORS' CONTRIBUTIONS}

The present study was designed and performed by the author himself.

\section{CONFLICTS OF INTEREST}

There are no conflicts of interest of any sort.

\section{REFERENCES}

1. Longstreth GF. Definition and classification of irritable bowel syndrome: Current consensus and controversies. Gastroenterol Clin North Am 2005;34:173-87.

2. Grundmann O, Yoon SL. Irritable bowel syndrome: Epidemiology, diagnosis and treatment: An update for health-care practitioners. J Gastroenterol Hepatol 2010;25:691-9.

3. American College of Gastroenterology Task Force on Irritable Bowel Syndrome, Brandt LJ, Chey WD, Foxx-Orenstein AE, Schiller LR, Schoenfeld PS, et al. An evidence-based position statement on the management of irritable bowel syndrome. Am J Gastroenterol 2009;104 Suppl 1:S1-35.

4. Katsinelos P, Lazaraki G, Kountouras J, Paroutoglou G, Oikonomidou I, Mimidis K, et al. Prevalence, bowel habit subtypes and medical careseeking behaviour of patients with irritable bowel syndrome in northern Greece. Eur J Gastroenterol Hepatol 2009;21:183-9.

5. Park JM, Choi MG, Kim YS, Choi CH, Choi SC, Hong SJ, et al. Quality of life of patients with irritable bowel syndrome in Korea. Qual Life Res 2009;18:435-46.

6. Shen YH, Nahas R. Complementary and alternative medicine for treatment of irritable bowel syndrome. Can Fam Physician 2009;55:143-8.

7. Longstreth GF, Thompson WG, Chey WD, Houghton LA, Mearin F, Spiller RC, et al. Functional bowel disorders. Gastroenterology 2006;130:1480-91

8. Lovell RM, Ford AC. Global prevalence of and risk factors for irritable bowel syndrome: A meta-analysis. Clin Gastroenterol Hepatol 2012;10:712-210000.

9. Hungin AP, Whorwell PJ, Tack J, Mearin F. The prevalence, patterns and impact of irritable bowel syndrome: An international survey of 40,000 subjects. Aliment Pharmacol Ther 2003;17:643-50.

10. DiBonaventura M, Sun SX, Bolge SC, Wagner JS, Mody R. Healthrelated quality of life, work productivity and health care resource use associated with constipation predominant irritable bowel syndrome. Curr Med Res Opin 2011;27:2213-22.

11. Dibonaventura MD, Prior M, Prieto P, Fortea J. Burden of constipationpredominant irritable bowel syndrome (IBS-C) in France, Italy, and the United Kingdom. Clin Exp Gastroenterol 2012;5:203-12

12. Fortea J, Prior M. Irritable bowel syndrome with constipation: A European-focused systematic literature review of disease burden. J Med Econ 2013;16:329-41.

13. Camilleri M, Tack JF. Current medical treatments of dyspepsia and irritable bowel syndrome. Gastroenterol Clin North Am 2010;39:481-93.

14. Jadallah KA, Kullab SM, Sanders DS. Constipation-predominant irritable bowel syndrome: A review of current and emerging drug therapies. World J Gastroenterol 2014;20:8898-909.

15. Moyad MA. Brewer's/baker's yeast (Saccharomyces cerevisiae) and preventive medicine: Part II. Urol Nurs 2008;28:73-5.

16. Chilton SN, Burton JP, Reid G. Inclusion of fermented foods in food guides around the world. Nutrients 2015;7:390-404.

17. Nakamura T, Agata K, Mizutani M, Iino H. Effects of brewer's yeast cell wall on constipation and defecation in experimentally constipated rats. Biosci Biotechnol Biochem 2001;65:774-80.

18. Pineton de Chambrun G, Neut C, Chau A, Cazaubiel M, Pelerin F, Justen $\mathrm{P}$, et al. A randomized clinical trial of Saccharomyces cerevisiae versus placebo in the irritable bowel syndrome. Dig Liver Dis 2015;47:119-24

19. Pinheiro I, Robinson L, Verhelst A, Marzorati M, Winkens B, den Abbeele PV, et al. A yeast fermentate improves gastrointestinal discomfort and constipation by modulation of the gut microbiome: Results from a randomized double-blind placebo-controlled pilot trial. BMC Complement Altern Med 2017;17:441

20. Spiller R, Pélerin F, Cayzeele Decherf A, Maudet C, Housez B, Cazaubiel M, et al. Randomized double blind placebo-controlled trial of Saccharomyces cerevisiae CNCM I-3856 in irritable bowel syndrome: Improvement in abdominal pain and bloating in those with predominant constipation. United European Gastroenterol J 2016;4:353-62.

21. Ashraf K, Syedadnan A, Shah A, Mujeeb M. Determination of 10-gingerol in Indian ginger by validated hptlc method of samples collected across subcontinent of India. Int $\mathrm{J}$ Pharm Pharm Sci 2016;8:190-3

22. Ashraf K, Sultan S, Shah S. Phychemistry, phytochemical, pharmacological and molecular study of Zingiber officinale Roscoe: A review. Inter J Pharm Pharm Sci 2017;9:8-16

23. Bordia A, Verma SK, Srivastava KC. Effect of ginger (Zingiber officinale Rosc.) and fenugreek (Trigonella foenumgraecum L.) on blood lipids, blood sugar and platelet aggregation in patients with coronary artery disease. Prostaglandins Leukot Essent Fatty Acids 1997;56:379-84.

24. Ghayur MN, Gilani AH. Ginger lowers blood pressure through blockade of voltage-dependent calcium channels. J Cardiovasc Pharmacol 2005;45:74-80.

25. Maghbooli M, Golipour F, Moghimi Esfandabadi A, Yousefi M. Comparison between the efficacy of ginger and sumatriptan in the ablative treatment of the common migraine. Phytother Res 2014;28:412-5.

26. Borrelli F, Capasso R, Aviello G, Pittler MH, Izzo AA. Effectiveness and safety of ginger in the treatment of pregnancy-induced nausea and vomiting. Obstet Gynecol 2005;105:849-56.

27. Tianthong W, Phupong V. A randomized, double-blind, placebocontrolled trial on the efficacy of ginger in the prevention of abdominal distention in post cesarean section patients. Sci Rep 2018;8:6835.

28. van Tilburg MA, Palsson OS, Ringel Y, Whitehead WE. Is ginger effective for the treatment of irritable bowel syndrome? A double blind randomized controlled pilot trial. Complement Ther Med 2014:22:17-20.

29. Ghayur MN, Gilani AH. Pharmacological basis for the medicinal use of ginger in gastrointestinal disorders. Dig Dis Sci 2005;50:1889-97.

30. Drossman DA, Chang L, Bellamy N, Gallo-Torres HE, Lembo A, Mearin F, et al. Severity in irritable bowel syndrome: A Rome foundation working team report. Am J Gastroenterol 2011;106:1749-59.

31. Francis CY, Morris J, Whorwell PJ. The irritable bowel severity scoring system: A simple method of monitoring irritable bowel syndrome and its progress. Aliment Pharmacol Ther 1997;11:395-402.

32. Bengtsson M, Hammar O, Mandl T, Ohlsson B. Evaluation of gastrointestinal symptoms in different patient groups using the visual analogue scale for irritable bowel syndrome (VAS-IBS). BMC Gastroenterol 2011;11:122

33. Drossman DA, Morris CB, Schneck S, Hu YJ, Norton NJ, Norton WF, et al. International survey of patients with IBS: Symptom features and their severity, health status, treatments, and risk taking to achieve clinical benefit. J Clin Gastroenterol 2009:43:541-50.

34. Gallegos-Orozco JF, Foxx-Orenstein AE, Sterler SM, Stoa JM. Chronic constipation in the elderly. Am J Gastroenterol 2012;107:18-25.

35. De Giorgio R, Ruggeri E, Stanghellini V, Eusebi LH, Bazzoli F, Chiarioni G, et al. Chronic constipation in the elderly: A primer for the gastroenterologist. BMC Gastroenterol 2015;15:130.

36. Pickett-Blakely O. Obesity and irritable bowel syndrome: A comprehensive review. Gastroenterol Hepatol (N Y) 2014;10:411-6.

37. Rey E, Talley NJ. Irritable bowel syndrome: Novel views on the epidemiology and potential risk factors. Dig Liver Dis 2009;41:772-80.

38. El-Salhy M. Irritable bowel syndrome: Diagnosis and pathogenesis. World J Gastroenterol 2012;18:5151-63.

39. O'Malley D, Quigley EM, Dinan TG, Cryan JF. Do interactions between stress and immune responses lead to symptom exacerbations in irritable bowel syndrome? Brain Behav Immun 2011:25:1333-41.

40. Blanchard EB, Lackner JM, Jaccard J, Rowell D, Carosella AM, Powell C, et al. The role of stress in symptom exacerbation among IBS patients. J Psychosom Res 2008;64:119-28.

41. Nakade Y, Fukuda H, Iwa M, Tsukamoto K, Yanagi H, Yamamura T, et al. Restraint stress stimulates colonic motility via central corticotropinreleasing factor and peripheral 5-HT3 receptors in conscious rats. Am J Physiol Gastrointest Liver Physiol 2007;292:G1037-44.

42. Konturek SJ, Brzozowski T, Konturek PC, Zwirska-Korczala K, Reiter RJ. Day/night differences in stress-induced gastric lesions in rats with an intact pineal gland or after pinealectomy. J Pineal Res 2008:44:408-15.

43. Lyte M, Vulchanova L, Brown DR. Stress at the intestinal surface: Catecholamines and mucosa-bacteria interactions. Cell Tissue Res 2011;343:23-32.

44. Sánchez B, Delgado S, Blanco-Míguez A, Lourenço A, Gueimonde M, Margolles A, et al. Probiotics, gut microbiota, and their influence on host health and disease. Mol Nutr Food Res 2017;61:1-15.

45. Sarkar A, Lehto SM, Harty S, Dinan TG, Cryan JF, Burnet PWJ, et al. Psychobiotics and the manipulation of bacteria-gut-brain signals. 
Trends Neurosci 2016;39:763-81.

46. Tillisch K, Labus J, Kilpatrick L, Jiang Z, Stains J, Ebrat B, et al. Consumption of fermented milk product with probiotic modulates brain activity. Gastroenterology 2013;144:1394-401, 1401.e1-4.

47. Crouzet L, Gaultier E, Del'Homme C, Cartier C, Delmas E, Dapoigny M, et al. The hypersensitivity to colonic distension of IBS patients can be transferred to rats through their fecal microbiota. Neurogastroenterol Motil 2013;25:e272-82.
48. O'Mahony SM, Marchesi JR, Scully P, Codling C, Ceolho AM, Quigley EM, et al. Early life stress alters behavior, immunity, and microbiota in rats: Implications for irritable bowel syndrome and psychiatric illnesses. Biol Psychiatry 2009;65:263-7.

49. Cayzeele-Decherf A, Pélerin F, Leuillet S, Douillard B, Housez B, Cazaubiel M, et al. Saccharomyces cerevisiae CNCM I-3856 in irritable bowel syndrome: An individual subject meta-analysis. World J Gastroenterol 2017;23:336-44. 